\title{
Você tem fome de quêe: 0 jornalismo gastronômico na cultura de consumo contemporânea brasileira
}

\author{
Renata Maria do Amaral
}

\section{Resumo}

Este artigo analisa como o jornalismo gastronômico se insere na cultura de consumo contemporânea brasileira. Para tanto, recorremos a conceitos como hedonismo imaginativo, de Campbell; gosto, distinção e estilo de vida, de Bourdieu; e renovação do desejo pela moda, de Lipovetsky. 0 corpus utilizado é 0 caderno Comida, da Folha de S.Paulo, pioneiro como suplemento independente sobre 0 assunto entre 1988 e 1992 e relançado em 2011. 0 fenômeno cultural da gastronomia é observado no contexto do crescimento da classe média no país, quando mais pessoas passam a se alimentar fora de casa e a pensar mais sobre o que comem, buscando informações sobre 0 assunto para orientar suas escolhas.

Palavras-Chave

Jornalismo gastronômico. Cultura de consumo. Gosto.

Renata Maria do Amaral | reamara|@gmail.com Doutoranda em Comunicação pela Universidade Federal de Pernambuco - UFPE

\section{Imaginação insaciável: \\ o hedonismo em Campbell}

Muito se fala sobre vivermos hoje em uma sociedade ou em uma cultura de consumo. Mas, afinal, o que define o consumismo moderno?

Slater (2002) afirma que o consumo é um processo cultural em qualquer época, mas que a cultura de consumo é um termo que deve ser usado com exclusividade para delimitar "o modo dominante de reprodução cultural desenvolvido no Ocidente durante a modernidade" (p. 17). Esse sistema é visto, geralmente, como expressão do livre arbítrio individual, mas existem fatores que influenciam 0 consumo. Falaremos sobre alguns deles adiante.

Baseada na insaciabilidade, a cultura de consumo se configura como acontecimento historicamente inédito, no qual as necessidades são reformuladas sem parar:

Na maioria das culturas, a possibilidade de que as necessidades sejam insaciáveis revela uma patologia social ou moral (pecado, corrupção, decadência) ou um indicador muito particular de status das elites sociais (o excesso de exibição competitiva). Na cultura de consumo, única e exclusivamente, a necessidade ilimitada - 0 
desejo constante de mais e a produção constante de mais desejos - é comumente considerada não apenas normal para seus membros, mas essencial para a ordem e o progresso socioeconômico. [...] A sociedade de mercado é sempre assombrada pela possibilidade de que as necessidades estejam satisfeitas ou subfinanciadas (p. 36).

A mercadoria peculiar da cultura de consumo, para Slater, não é necessariamente um bem material, mas principalmente uma representação (como a informação) ou uma experiência (como o lazer ou, podemos acrescentar, a gastronomia). A economia passa por um processo de desmaterialização. Nesse contexto, os desejos variam segundo as possibilidades que se apresentam:

\footnotetext{
Meus conhecimentos e necessidades serão completamente diferentes, dependendo de eu estar lidando com um meio ambiente onde eu caço e coleto alimentos (onde construo o mundo em termos de comestível e não-comestível, perigo versus presa fácil, relativamente à necessidade da fome), ou com um ambiente onde posso ir jantar fora, ou fazer um lanche rápido, preparar uma refeição num forno microondas, exigir ingredientes orgânicos e assim por diante. 0 que quero dizer é que não tenho simplesmente mais opções para satisfazer a mesma necessidade (fome); tenho necessidades muito mais numerosas (p. 104).
}

Insatisfeito com as explicações mais comuns sobre o consumo, que viam o fenômeno como uma necessidade instintiva, uma manipulação meramente publicitária ou uma tentativa de emulação do comportamento alheio, Campbell (2001) relacionou o espírito do consumismo moderno à ética romântica. Para ele, um misto de expectativa e frustração move o mecanismo dos desejos sempre insatisfeitos e rapidamente substituídos por outros: "0 aspecto mais característico do consumo moderno é essa insaciabilidade" (p. 58). À medida que as expectativas aumentam, também crescem as frustrações. A concepção de consumo preferida do autor não provém da economia, em que ele é visto como um processo de esgotamento dos bens produzidos, mas sim da ação social, em que os bens são parte de um comportamento conscientemente motivado. Sua dúvida, porém, resume-se da seguinte forma: como explicar a extinção de um desejo e sua posterior transformação em outro desejo?

Campbell defende que 0 hedonismo moderno é autônomo e imaginativo. A busca pelo prazer não é novidade: tanto o hedonismo tradicional quanto o moderno são "uma questão de conduta arrastada para a frente pelo desejo da antecipada qualidade de prazer que uma experiência promete dar" (p. 114). No entanto, no hedonismo moderno a estimulação é emocional e não apenas sensorial, e os estímulos reais são menos confiáveis do que a imaginação, que vira o fio condutor na criação do desejo, na forma de devaneio ou fantasia:

0 hedonismo moderno tende a ser encoberto e autoilusivo, isto é, os indivíduos empregam seus poderes imaginativos e criativos para construir imagens mentais que eles consomem pelo intrínseco prazer que elas proporcionam, uma prática que se descreve melhor como de devanear ou fantasiar (p. 114). 
A fantasia está ligada ao desejo de prazer. Como a realidade não oferece tanto prazer, ela surge como uma forma de hedonismo por meio de imagens que, embora ilusórias, são desfrutadas como se fossem reais. No jornalismo gastronômico, o desejo de intenso prazer gustativo pode ser verificado nas fotos de pratos em close, especialmente nas revistas, em que a impressão de alta qualidade ajuda no estímulo sensorial. Geralmente, as iguarias produzidas por chefs renomados vêm acompanhadas pela receita, mas podemos arriscar que poucos leitores ousam tentar reproduzir em casa esse complexo passo a passo: 0 simples contemplar a imagem já é, em si, fonte de prazer. Não foi por acaso que esse tipo de preparo de pratos feitos para impressionar e sair bem na foto ganhou 0 autoexplicativo nome de food porn.

Campbell distingue o devaneio e a fantasia: o primeiro engloba um desejo duplo - prazer obtido pelo devaneio em si e pela contemplação da sua realização -, enquanto o segundo se contenta em almejar a concretização do desejo. No devaneio, desejar pode ser tão interessante quanto efetivar o desejo. "Ao contrário da fantasia, portanto, o devaneio está intimamente ligado a um componentechave do hedonismo moderno, 0 anseio" (p. 125). 0 devaneio interfere no caminho entre o desejo e a consumação, ou seja, mistura os prazeres da fantasia e da realidade: "Enquanto para 0 homem tradicional a satisfação adiada significara simplesmente a experiência da frustração, para o homem moderno ela se torna um hiato feliz entre 0 desejo e a consumação que pode ser satisfeita com as alegrias do devanear" (p. 126).

Ainda comparando os modelos tradicional e moderno de hedonismo, a novidade entra como fator de diferenciação. No modelo tradicional, a imaginação não tem grande importância, pois os objetos de desejo já são conhecidos e o novo é evitado. No modelo moderno, ao contrário, como os objetos são desconhecidos, há liberdade para devanear à vontade. No momento de realização do desejo, contudo, dificilmente a perfeição do devaneio se concretiza: "A consumação do desejo é, portanto, uma experiência necessariamente desencantadora para o hedonista moderno" (p. 127). A ilusão se transfere para um novo objeto desconhecido, e o processo se repete $a d$ infinitum, o que explica o consumo insaciável:

Os indivíduos não procuram tanta satisfação dos produtos quanto prazer das experiências autoilusivas que constroem com suas significações associadas. (...) Encarada dessa maneira, a ênfase tanto na novidade quanto na insaciabilidade se torna compreensível (p. 130).

Para Campbell, o espírito do consumismo moderno não é materialista, ou seja, não diz respeito aos objetos, mas ao próprio anseio perenemente renovado. A imagem dos bens ganha mais importância do que os bens em si, o que explica 0 fato de as pessoas apreciarem olhar fotos de produtos inacessíveis para seus padrões de consumo, como é o caso das vitrines de lojas e revistas de gastronomia. É o que observa Moraes 
(2011), ao analisar a relação de frequentadoras de salões de beleza de bairros periféricos da capital pernambucana com a revista de celebridades Caras. A seção de receitas é considerada atrativa, porém serve apenas para contemplação, segundo suas entrevistadas. 0s ingredientes são caros e difíceis de encontrar, mas, mesmo assim, essas mulheres não se furtam a devanear com os pratos apresentados, imaginando como seriam seus sabores se pudessem ser experimentados.

Fenômenos modernos como a moda, sobre a qual abordaremos mais adiante, e até mesmo o amor romântico podem ser listados entre os exemplos do devanear: "0 ciclo de desejo - aquisição desilusão - desejo renovado é um aspecto geral do hedonismo moderno e se aplica tanto às relações interpessoais românticas quanto ao consumo de produtos culturais como roupas e discos" (p. 132-133). É por meio do exemplo da moda que Campbell insere mais um elemento na equação do hedonismo imaginativo: 0 gosto. "0 gosto é o fenômeno crucial que liga o hedonismo imaginativo à instituição da moda moderna pois, como sugere seu uso linguístico, o gosto abarca tanto a padronização dos prazeres como os processos do discernimento estético" (p. 137).

\section{Entre a necessidade e a liberdade: 0 gosto em Bourdieu}

É justamente o gosto uma das principais preocupações téoricas de Bourdieu (2007a), mas não é pelo caminho da estetização que ele segue e sim pelo da estilização. Enquanto Campbell apresenta uma visão que pode ser considerada inner-directed, ou seja, voltada para dentro, com foco no prazer, Bourdieu defende uma concepção other-directed, voltada para fora, com ênfase na distinção. Bourdieu vai de encontro à concepção de gosto como simples sensação física para se ater à formação do gosto na sociedade contemporânea. Assim, ele deixa de ser visto como uma espécie de "iluminação" destinada a poucas pessoas para passar a ser compreendido de acordo com as dinâmicas sociais.

0 autor considera que nada confere mais distinção do que ser capaz de preocupar-se com as escolhas cotidianas, tais como o cardápio, o vestuário ou a decoração da casa. Nesse caso, 0 destaque vai além da matéria, ou seja, do alimento em si, para chegar à maneira de servi-lo e à etiqueta à mesa (no entanto, segundo o autor, a burguesia peca ao chamar atenção demais para tais cuidados - seu esforço termina por transparecer e perde-se 0 efeito de naturalidade e despretensão que se almeja obter para aparentar distinção). Sua análise indica oposição entre as classes inferiores e superiores sempre de forma relacional: enquanto as primeiras privilegiam a quantidade, as segundas prezam pela qualidade. É a oposição entre o "gosto de necessidade", destinado a oferecer energia para 0 trabalho braçal, da forma mais efetiva e econômica possível, e o "gosto de liberdade ou de luxo", apropriado para resultar em prazer de degustação. Cabe lembrar que o que mais determina o gosto de alguém é justamente a negação do gosto do 
outro, como se apenas o próprio fosse o correto, 0 adequado, 0 "bom gosto", enfim. Eis por que, conforme Bourdieu, a aprendizagem na infância, no lar, não consegue ser substituída pelo ensino formal no caso da alimentação:

Nos gostos alimentares, poderíamos encontrar a marca mais forte e inalterável das aprendizagens primitivas, aquelas que sobrevivem mais tempo ao afastamento e desmoronamento do mundo de origem, mantendo de modo mais duradouro sua nostalgia: de fato, 0 mundo de origem é, antes de tudo, o mundo materno, 0 mundo dos gostos primordiais e dos alimentos originários, da relação arquetípica com a forma arquetíica do bem cultural, em que 0 dar prazer faz parte integrante do prazer e da disposição seletiva para o prazer que se adquire no prazer (p. 76).

Para Bourdieu (2007a), o gosto passa longe de ser um dom da natureza: as práticas culturais estão, ao contrário, ligadas à instrução e à origem social. "À hierarquia socialmente reconhecida das artes - e, no interior de cada uma delas -, dos gêneros, escolas ou épocas, corresponde a hierarquia social dos consumidores. Eis o que predispõe os gostos a funcionar como marcadores privilegiados da 'classe"' (p. 9). 0 autor remete ao gosto no sentido gastronômico para explicar como há uma percepção errônea do gosto cultural como algo inato e não aprendido:

0 duplo sentido do termo "gosto" - que, habitualmente, serve para justificar a ilusão da geração espontânea que tende a produzir esta disposição culta, ao apresentar-se sob as aparências da disposição inata - deve servir, desta vez, para lembrar que o gosto, enquanto "faculdade de julgar valores estéticos de maneira imediata e intuitiva" é indissociável do gosto no sentido de capacidade para discernir os sabores próprios dos alimentos que implica a preferência por alguns deles (p. 95).

Bourdieu (1982) esclarece a conexão entre gosto de classes e estilo de vida. A cada posição no espaço social corresponde um estilo de vida diferente, que funciona como uma espécie de reflexo do capital social e econômico sobre o capital simbólico dos bens de consumo. Em suas palavras:

0 gosto, propensão e aptidão à apropriação (material e/ou simbólica) de uma determinada categoria de objetos ou práticas classificadas e classificadoras, é a fórmula generativa que está no princípio do estilo de vida. 0 estilo de vida é um conjunto unitário de preferências distintivas que exprimem, na lógica específica de cada um dos subespaços simbólicos, mobília, vestimentas, linguagem ou héxis corporal, a mesma intenção expressiva, princípio da unidade de estilo que se entrega diretamente à intuição $\mathrm{e}$ que a análise destrói ao recortá-lo em universos separados (p. 83-84).

Saber se determinado indivíduo bebe Pernod, espumante, água mineral, vinho Bordeaux, champanhe ou uísque é suficiente, segundo o autor, para caracterizá-lo socialmente, até mais do que suas escolhas no universo artístico. Quando se fala do gosto de luxo, por exemplo, ocorre o que Bourdieu chama de estilização da vida, "decisão sistemática que orienta e organiza as práticas mais diversas, escolha de um vinho e de um queijo ou decoração de uma casa de campo" (p. 87).

Em outro estudo, que alça as grifes da alta costura a objeto de pesquisa, Bourdieu (2008) explica 0 
fascínio que um nome pode conferir a um objeto. Segundo ele, a raridade não se encontra no objeto em si, mas sim no seu produtor, que possui o que ele chama de "poder mágico". Tal poder modifica 0 valor simbólico e econômico dos bens de luxo, e essa operação de transferência conta com 0 auxílio dos meios de comunicação na circulação das informações sobre 0 assunto. 0 autor trata da moda e das revistas de vestuário, mas é possível traçar um paralelo entre o que acontece com os restaurantes e a crítica de gastronomia, detentora de um capital de autoridade que pode ajudar a definir o sucesso ou o fracasso de um estabelecimento, cujos chefs podem se tornar verdadeiras celebridades midiáticas.

Ao analisar o mercado dos bens simbólicos, Bourdieu (2007b) explica como se dá 0 estabelecimento de um campo autônomo da produção erudita. 0 papel da crítica, que muitas vezes faz parte também do campo da produção, não é de interpretar obras mais complexas, mas sim de "fornecer uma interpretação 'criativa' para uso dos 'criadores'. Destarte, constituem-se 'sociedades de admiração mútua', pequenas seitas fechadas em seu esoterismo e, ao mesmo tempo, surgem os signos de uma nova solidariedade entre 0 artista e 0 crítico" (p. 106-107). Não é o caso de entrar na querela se a gastronomia pode ser considerada arte ou não, mas o fato é que 0 jornalismo sobre 0 assunto vem hasteando bandeiras voltadas para fincar determinados movimentos, como é 0 caso da cozinha espanhola contemporânea. A mídia pode não ser a única responsável pelas modas ou manias alimentares, mas, decerto, interfere no que vira tendência.

0 autor defende que as classes em ascensão são os alvos preferenciais desses manuais do bem viver. Enquanto as classes superiores podem inovar sem receio, as ascendentes dependem como nenhuma outra das instâncias de legitimação, as quais acabam por torná-las mais conformistas e conservadoras. 0 consumo ávido de revistas de decoração, moda e gastronomia para assegurar 0 "bom gosto" busca um acesso rápido a um estilo de vida anteriormente inacessível. Não se trata, no entanto, de uma simples apropriação imediata do gosto alheio, mas de uma mediação mais complexa, conforme explica Rocha (2002):

0 gosto por certos bens não pode ser atribuído à disseminação vertical e homogênea de certos hábitos de consumo, quer seja através da publicidade, quer seja através de outros âmbitos de difusão cultural. 0 consumo estilizado define-se por uma manipulação dos atributos simbólicos dos produtos, não apenas pelo discurso publicitário, mas também pelos sujeitos em suas práticas cotidianas (p. 44).

Como resume a autora, o consumo moderno apresenta como princípios tanto a estilização, "ou sua conversão em espaço de construção e embate das identidades sociais" (p. 22), quanto a estetização, "uma relação com os produtos cada vez mais mediada por imagens e fantasias" (p. 22). Podemos relacionar essas imagens e fantasias com a moda, outro fator organizador do consumo e instigador de insaciabilidade, do querer sempre mais. 


\section{Desejo renovado: a moda em Lipovetsky}

Para tanto, é inevitável recorrer aos estudos de Lipovetsky (1997), ressalvando que sua visão da moda como espaço de liberdade, indiferente a quaisquer pressões externas, é antagônica à de Bourdieu, para quem o gosto, conforme já vimos, é resultado de uma equação de variantes sociais, econômicas e culturais. Entretanto, vale a pena lançar mão do autor porque algumas das observações que ele faz sobre a moda se encaixam com precisão à gastronomia, também embalada por renovações periódicas e tendências em mutação:

Com a Alta Costura aparece a organização da moda tal como a conhecemos ainda hoje, pelo menos em suas grandes linhas: renovação sazonal, apresentação de coleções por manequins vivos, e sobretudo uma nova vocação, acompanhada de um novo status social do costureiro (p. 79).

A Alta Gastronomia pode ser comparada à Alta Costura quando pensamos no status do estilista e do chef de cozinha. Ambos passam a ser vistos como criadores dotados de talento exclusivo. Afirma Lipovetsky: "A distância em relação ao passado é nítida, marcada: de artesão 'rotineiro' e tradicional, o costureiro, agora modelista, tornou-se 'gênio' artístico moderno" (p. 80). Já defendemos em trabalho anterior (AMARAL, 2006) o pertencimento da gastronomia ao campo cultural de forma mais ampla - até mesmo jornalisticamente, a comida se localiza nos cadernos de cultura quando não conta com suplementos exclusivos - e não iremos repetir a discussão aqui. A ligação com 0 campo artístico no sentido estrito, porém, só é defendida por alguns autores e não encontra paralelo em Lipovetsky com relação à moda. 0 autor considera que 0 modelista tem poder de criação, mas ele é limitado aos trâmites mercadológicos, 0 que não acontece com escritores ou pintores:

De direito, o modelista é um criador "livre", sem limites; de fato, à frente de um empreendimento industrial e comercial, o grande costureiro vê sua autonomia criadora limitada pelos costumes do tempo, pelo estilo em voga, pela natureza particular do produto realizado - o traje que deve agradar a estética das pessoas e não apenas satisfazer o puro projeto criador (p. 80).

Pendores artísticos à parte, os costureiros têm sua criatividade restringida pelo público e pela imprensa especializada, que divulga o que é tendência naquela estação. Não é por acaso que elementos das coleções de estilistas distintos se repetem: "A unidade das coleções não é, de modo algum, o signo de um acordo secreto entre os costureiros [...], não significa a onipotência dos modelistas, sendo, antes, 0 efeito do encontro de uma burocracia estética com a lógica da demanda" (p. 99).

Se $o$ lado mais criativo - ou, como defendem alguns, artístico - das vestimentas é explorado na Alta Costura, cabe ao prêt-à-porter levar a moda dos ateliês para as ruas em versões adaptadas, ou melhor, simplificadas. De acordo com o autor, o desejo de moda aumentou depois da Segunda Guerra Mundial, atingindo toda a sociedade e não 
apenas as classes abastadas. Lipovetsky articula o cinema e a imprensa à cultura hedonista $\mathrm{e}$ individualista surgida então:

Na raiz do prêt-à-porter, há essa democratização última dos gostos de moda trazidas pelos ideais individualistas, pela multiplicação das revistas femininas e pelo cinema, mas também pela vontade de viver o presente e estimulada pela nova cultura hedonista de massa. A elevação do nível de vida, a cultura do bem-estar, do lazer e da felicidade imediata acarretaram a última etapa da legitimação e da democratização das paixões de moda. Os signos efêmeros e estéticos da moda deixaram de aparecer, nas classes populares, como um fenômeno inacessível reservado aos outros; tornaram-se uma exigência de massa, um cenário de vida decorrente de uma sociedade que sacraliza a mudança, o prazer, as novidades. A era do prêt-à-porter coincide com a emergência de uma sociedade cada vez mais voltada para o presente, euforizada pelo Novo e pelo consumo (p. 115).

A cultura do consumo, cabe frisar, já dava sinais de vida antes disso. Grant McCracken (2003), ao retomar o livro Dream worlds: mass consumption in nineteenth century France, de Rosalind Williams, lembra que 0 fim da corte francesa no século 18 trouxe uma mudança importante em relação aos padrões de consumo, tanto aristocráticos quanto plebeus:

A produção de certos bens transferiu-se do reino privado da domesticidade nobre para a esfera pública do mercado. Nos anos de 1790 , os chefs se mudaram dos hotéis aristocráticos para os restaurantes públicos, enquanto as costureiras e os alfaiates que antes haviam servido a patrões nobres abriram lojas públicas. De modo crescente, o consumo público, mais que o privado, passava a ser o foco do trabalho dos produtores dos bens de luxo (p. 44).
Democratização pode não ser a palavra

mais apropriada, mas as mudanças sociais e econômicas, de fato, acarretam alterações significativas nos padrões e modos de consumo. Bens materiais ou imateriais antes restritos às camadas superiores da população, conforme o contexto da época, podem passar a ser disseminados para as camadas médias. 0 produto passa a ser acessível a quem puder pagar por ele. É o que acontece no Brasil contemporâneo, como veremos a seguir.

\section{Gastronomia como fenômeno cultural: o caderno Comida da Folha de S.Paulo}

Para observar como se constrói uma ideia de gastronomia na imprensa brasileira e como se dá sua relação com a cultura de consumo, vamos recorrer ao caderno Comida, da Folh a de S.Paulo, por um motivo simples: apesar de só ter sido relançado em 2011 em sua segunda e atual fase, o suplemento teve uma primeira fase entre 1988 e 1992, sendo pioneiro em relação a outros veículos de comunicação. Naquela época, o conteúdo jornalístico ligado à alimentação era formado prioritariamente por receitas, como explica 0 então editor de Comida (e atual crítico de gastronomia do jornal) Josimar Melo:

A Folha foi pioneira na cobertura de gastronomia no país, com o lançamento do caderno Comida, que circulou entre 1988 e 1992. "Naquela época, 0 que se publicavam eram receitas. 0 interesse pela comida como cultura, pelo vinho e pelos chefs estava despertando. Nosso caderno serviu como uma grande vitrine para esse despertar", 
diz Josimar Melo, crítico da Folha e editor da primeira versão do Comida (COMIDA, 2011).

Na impossibilidade de abranger um corpus maior neste artigo, optamos por apresentar a primeira edição de cada uma das fases da editoria. Comecemos pela edição de 23 de setembro de 1988, quando Comida passa a ser publicado às sextas-feiras, em quatro páginas independentes encartadas no caderno cultural Ilustrada. A reportagem de capa é uma seleção dos melhores restaurantes paulistanos de acordo com os leitores da própria Folha de S.Paulo, entrevistados em uma pesquisa de opinião do Instituto de Pesquisas Datafolha. Ao explicar a metodologia utilizada, o texto já oferece boas dicas de por que era importante, naquele momento, lançar uma nova seção do jornal exclusivamente sobre comida:

0 universo consultado é respeitável: a base de pesquisa foram os assinantes da Folha, num total de 406 consultas. É um segmento social que pode ter o privilégio de frequentar restaurantes com certa assiduidade. Mais da metade come fora entre uma e duas vezes por semana, e outros $27 \%$ de uma a duas vezes por mês. Fora os $10 \%$ que têm ainda maior assiduidade (DADOS, 1988).

0 jornal conhece seu público-alvo e percebe que ele adere, cada vez mais, à refeição fora de casa. Apresenta, ainda, um perfil do restaurateur Massimo Ferrari, dono do Massimo, eleito o melhor de São Paulo, na capa. Indicação de vinhos estrangeiros, receitas com produtos da estação e guia de restaurantes completam a edição, que ainda ensina como usar alcachofra e traz um pouco da história do ingrediente. É perceptível um didatismo de quem está apresentando ao leitor um novo insumo que ele provavelmente ainda não conhece. Podemos detectar o devaneio no sentido defendido por Campbell (2001): desejar algo novo e desconhecido já é, em si, um prazer.

Historicamente, em seus cinco anos de duração, a editoria Comida viu surgir, em 16 de março de 1990, o Plano Collor I. Além do congelamento das poupanças dos brasileiros, 0 então presidente Fernando Collor de Mello deu início à abertura comercial do país. Para aumentar a competição no mercado interno, as tarifas de importação foram gradualmente diminuídas. Não cabe a este artigo discutir as consequências dessa decisão para o Brasil de modo geral, mas, especificamente, o impacto na alimentação: é quando começam a chegar produtos antes desconhecidos da população, que só podiam ser comprados em viagens ao exterior.

0 caderno deixou de ser publicado em 14 de fevereiro de 1992, quando o conteúdo sobre 0 assunto passou a sair, com menos páginas, no caderno Fim de Semana e, a partir de 1996, na Ilustrada. Apenas 19 anos depois, em 2011, Comida volta à cena. Concorrente direto da Folha de S.Paulo, o jornal O Estado de S. Paulo já havia lançado seu suplemento Paladar em setembro de 2005. Na mesma época, a tendência se espalha para outras praças, como a capital pernambucana. Recife ganha novos cadernos de gastronomia em seus três principais jornais diários: nascem 
o Sabores, na Folha de Pernambuco (março de 2006); o Boa Mesa, no Jornal do Commercio (setembro de 2008); e 0 Gastrô, no Diário de Pernambuco (novembro de 2010).

0 contexto histórico, social e econômico agora é outro, como bem define a matéria da Ilustrada que anuncia o novo suplemento Comida:

"Desprovido dos jargões gastronômicos, 0 caderno surge quando, com a expansão da renda dos brasileiros, mais leitores passam a frequentar os restaurantes" (COMIDA, 2011). 0 texto explicita ainda que a ideia da nova seção é focar na prestação de serviços - ou seja, em informações que possam efetivamente ser "usadas" pelos leitores em seu cotidiano, como dicas de novas casas - e nas mudanças culturais relacionadas à alimentação.

Impossível não citar o crescimento do consumo no país na primeira década dos anos 2000, nos governos dos presidentes Luiz Inácio Lula da
Silva e Dilma Rousseff, como um dos fatores que contribuíram diretamente para essa explosão do interesse pela gastronomia nos veículos de comunicação. Com mais dinheiro no bolso, as pessoas passam a gastar mais, inclusive nos momentos de lazer, que englobam comer fora de casa. 0 incremento da classe média pode ser compreendido com maior precisão a seguir (FIG. 1):

As classes D e E foram reduzidas a menos da metade, enquanto a classe $\mathrm{C}$ ganhou mais de 40 milhões de pessoas entre 2005 e 2011. As classes A e B, por sua vez, receberam um incremento de mais de 50\% no mesmo período. Se em 2005 as classes A, B e C somadas não alcançavam o total das classes D e E, hoje elas respondem por quase três quartos do total de brasileiros. Os dados são da pesquisa 0 Observador Brasil 2012, encomendada pela Cetelem BGN à Ipsos Public Affairs, a fim de compreender o novo padrão de consumo dos brasileiros. Foram realizadas 1.500 entrevistas pessoais domiciliares com questionário estruturado em 70 cidades.

Figura 1: Mobilidade social
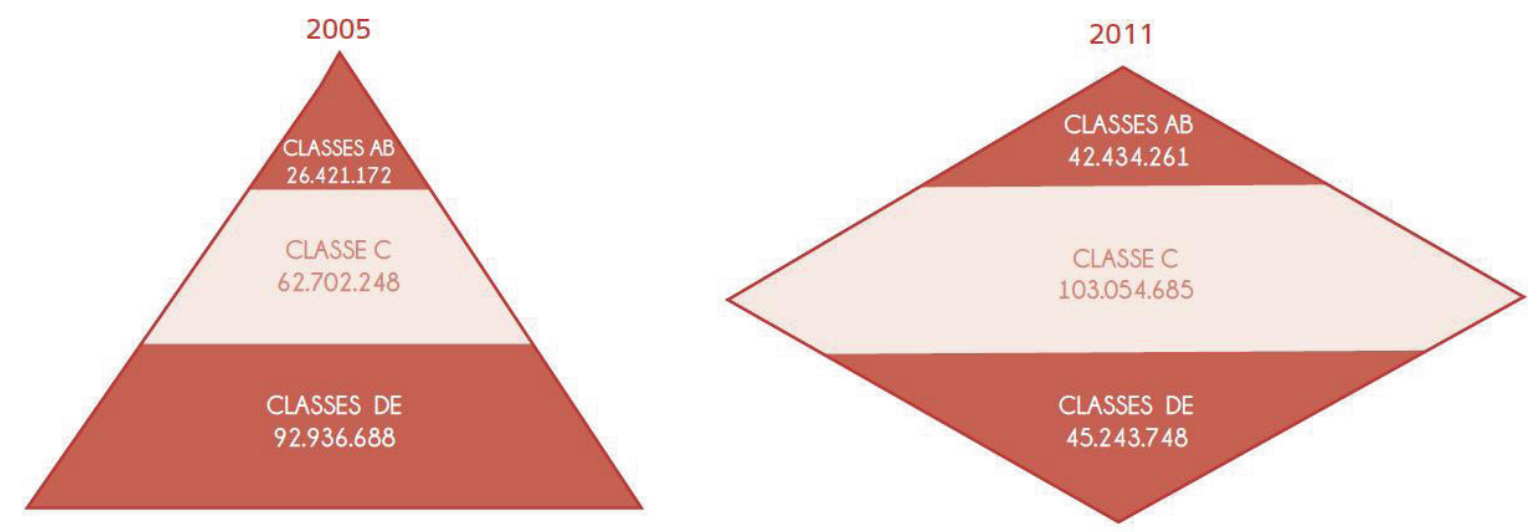
Essa sondagem não trata dos gastos com alimentação fora de casa, mas apresenta lazer/ viagem em terceiro lugar (25\%) na pretensão de compra para 0 ano seguinte, atrás apenas de móveis (31\%) e eletrodomésticos (30\%) e à frente de carro, televisão, computador e outros itens. Ao lado de bens concretos, aparecem aqueles de caráter imaterial, ligados à experiência, preconizados por Campbell (2001) e Slater (2002) - no caso, viagens, refeições, sessões de cinema e espetáculos em geral.

Divulgada na revista Época (CAIRO; SALOMÃO, 2010) e mais específica para o interesse deste artigo, a pesquisa "Alimentação fora do lar na visão do consumidor brasileiro", realizada pela consultoria de consumo especializada em varejo GS\&MD, indica que $31 \%$ dos gastos com alimentação no Brasil são destinados para refeições fora de casa ou entregues em domicílio. Neste quesito, o país perde apenas para Estados Unidos (41\%), Portugal (39\%), Reino Unido (38\%) e Espanha (32\%). Os dados são de 2010 - em 2002, 0 índice nacional era de apenas $24 \%$. A análise aponta três motivações para 0 aumento: 0 crescimento econômico, com ênfase na classe média; a inserção das mulheres no mercado de trabalho, e o maior número de domicílios unipessoais, cujos habitantes preferem a praticidade de se alimentar em restaurantes a ter que preparar alimentos apenas para si mesmos. Outro padrão detectado pela sondagem: 0 brasileiro almoça fora de casa nos dias úteis, no intervalo do trabalho, e janta nos fins de semana, nos momentos de lazer.
0 suplemento Comida surge em 2011, portanto, para atender a essa renovada demanda por informação sobre 0 tema. Acompanhando 0 movimento da gastronomia no Brasil desde a década de 1980, o crítico Josimar Melo escreve, ao lado da matéria de lançamento do caderno, um artigo fazendo um balanço dos 25 anos anteriores:

A gastronomia foi assumida como paixão: como trabalho criativo, lazer, objeto de cursos universitários e conversas de botequim. Passou a ser reconhecida como fenômeno cultural, digno de ser estudado e defendido. E seus protagonistas, os chefs, ganharam admiração e respeito. As últimas décadas mostraram que cozinhar exige habilidade, conhecimento e suor e, no caso dos grandes chefs, genialidade. 0 reconhecimento dessa dimensão foi uma grande aquisição que marca o nosso tempo (MELO, 2011).

É como fenômeno cultural, e não como uma lista de ingredientes e de modos de preparo, que a gastronomia aparece no caderno. A edição de lançamento, em 12 de maio de 2011, tem 16 páginas, quatro vezes o tamanho da primeira edição da fase anterior, quase duas décadas antes (depois, a edição se estabiliza entre seis e dez páginas, a depender da quantidade de anúncios, alguns de página inteira). Um detalhe sintomático: apenas três receitas breves marcam presença no avantajado caderno. Agora que isso é possível, comer em casa não parece mais tão estimulante quanto comer fora.

Para renovar constantemente o desejo, aparece a moda, conforme preconizada por Lipovetsky (1997), também na alimentação: as tendências 
e as novidades são desejadas, enquanto o velho some de cartaz. Coquetel de camarão ou delícia de abacaxi remetem ao passado e aparecem apenas como recordação ou como algo "brega", ultrapassado. Desnecessário dizer que as manias de hoje são os ingredientes renegados de amanhã, como já parece ser 0 caso da famigerada trinca tomate seco, rúcula e muçarela de búfala, considerada indispensável na década de 1990. A mídia tem participação importante nessas ondas, ao mesmo tempo refletindo-as e alimentando-as.

0 didatismo, com vistas a fazer o leitor aprender mais sobre comida, é explícito: há reportagens ilustradas sobre como funcionam as praças da cozinha do restaurante ou sobre quais cortes da carne de porco devem ser assados, braseados, fritos, guisados, grelhados ou salteados. Ao lado da barata carne de porco, surge até uma pauta sobre caviar, mas mostrando opções mais em conta (ou menos caras). Outra página rica em fotos indica onde comprar utensílios usados de restaurantes que acabaram de fechar as portas. A crítica, sempre escrita por Josimar Melo, apresenta uma casa mais requintada e outra mais acessível. É, segundo o conceito de Bourdieu (2007a), um estilo de vida que passa a ser difundido pelos jornais e revistas, que funcionam como manuais do bem viver, indicando ao novo mercado consumidor como se portar com seu recém-adquirido gosto de luxo.

A valorização das fotos é muito maior em relação à fase anterior, como pode ser verificado nas capas das duas edições (FIG. 2). 0 recurso do uso de cores ainda não era utilizado na primeira fase, mas, ainda assim, pode-se perceber que a comida se aproxima do food porn, cuidadosamente estetizada, clicada para dar água na boca e despertar o desejo do leitor-consumidor. Surge a função de food stylist, profissional responsável por todos os truques que deixam a imagem mais apetitosa.

As chamadas na capa principal - não do caderno Comida, mas do jornal inteiro, para anunciar 0 lançamento dos suplementos - também mostram 0 crescimento do status conferido à gastronomia. Enquanto a edição de 1988 traz uma chamada no pé da página, ocupando duas colunas na diagramação, a edição de 2011 anuncia a novidade no topo da página, acima da manchete, em seis colunas, com foto grande e colorida. Além da pauta principal sobre carne de porco, vários colunistas também são anunciados, assim como a versão on-line do novo suplemento (FIG. 3).

Como pudemos ver nesta breve análise, o jornalismo gastronômico possui papel fundamental na porção da cultura de consumo contemporânea brasileira que se relaciona à alimentação. Respondendo àquela velha canção dos anos 1980, "Comida", da banda Titãs, citada no título deste artigo, a fome, cada vez mais, não é de qualquer coisa. Ela depende de uma série de fatores ligados ao estilo de vida do consumidor (ou almejado por ele), à estética dos pratos e às modas que vão e vêm. 0 gosto não é um dom divino, mas um intrincado complexo que combina essas e outras variáveis. Cabe ao jornalismo gastronômico estar atento a essas nuances. 

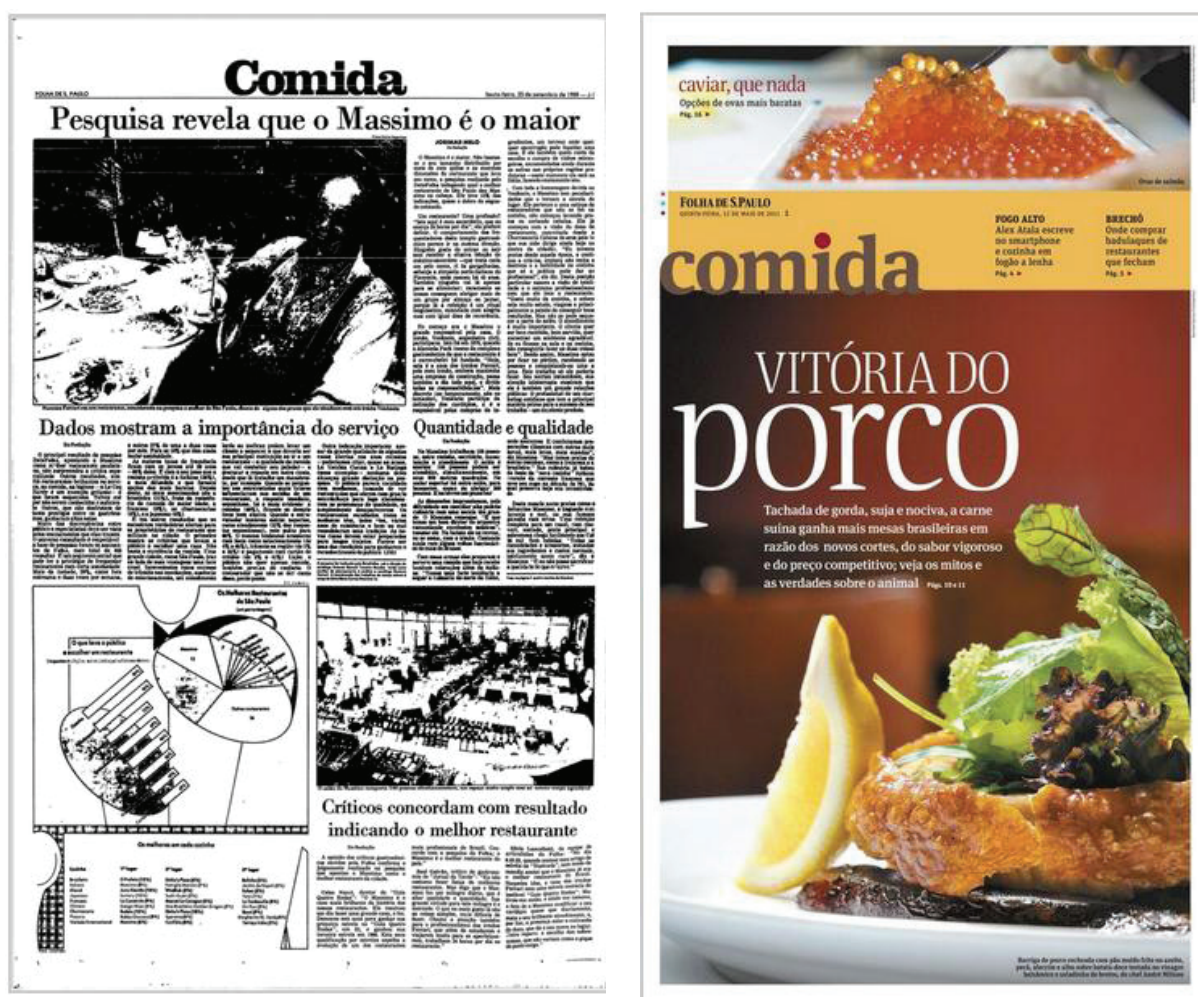

FONTE: Folha de S.Paulo

Figura 3: Capas da Folha de S.Paulo no lançamento de Comida em 1988 e 2011

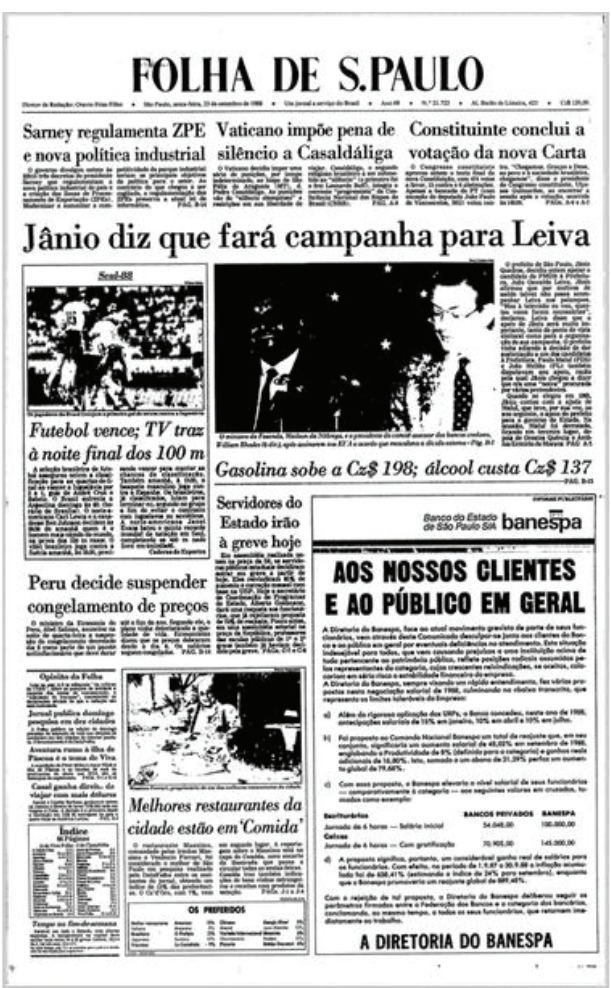

\section{FOLHA DE S.PAULO}

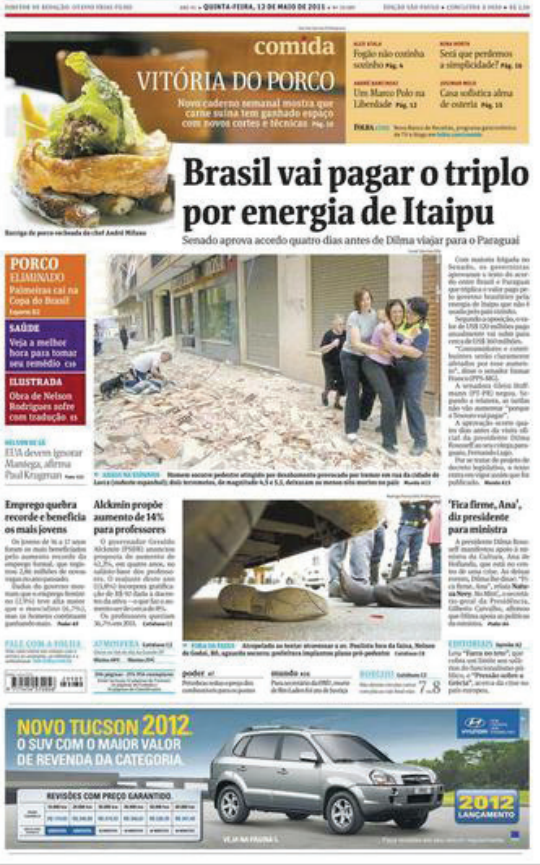




\section{Referências}

AMARAL, Renata Maria do. Gastronomia: prato do dia do jornalismo cultural. Dissertação de Mestrado em Comunicação. Recife: Universidade Federal de Pernambuco, 2006.

BOURDIEU, Pierre. A distinção: crítica social do julgamento. São Paulo: Edusp; Porto Alegre: Zouk, 2007a. . A produção da crença: contribuição para uma economia dos bens simbólicos. $3^{\mathrm{a}}$ ed. Porto Alegre: Zouk, 2008. "Gostos de classe e estilo de vida". In: ORTIZ, Renato (org.). Pierre Bourdieu. São Paulo: Ática, 1982. p. 82-121. . "0 mercado dos bens simbólicos" In: A economia das trocas simbólicas. São Paulo: Perspectiva, 2007b. p. 99-181.

CAIR0, Alberto; SALOMÃ0, Luiz. Quando o brasileiro come fora. Revista Época, São Paulo, 6 dez. 2010, Primeiro Plano, p. 34-35.

CAMPBELL, Colin. A ética romântica e o espírito do consumismo moderno. Rio de Janeiro: Rocco, 2001.

COMIDA, diversão e arte. Folha de S.Paulo, São Paulo, 11 mai. 2011. Ilustrada, p. 1.

DADOS mostram a importância do serviço. Folha de S.Paulo, São Paulo, 23 set. 1988. Comida, p. 1.

LIPOVETSKY, Gilles. 0 Império do Efêmero: a moda e seu destino nas sociedades modernas. São Paulo: Companhia das Letras, 1997.

MACCRACKEN, Grant. Cultura e consumo: novas abordagens ao caráter simbólico dos bens e das atividades de consumo. Rio de Janeiro: Mauad, 2003. MELO, Josimar. Como paixão, gastronomia floresce no mundo todo. Folha de S.Paulo, São Paulo, 11 mai. 2011. Ilustrada, p. 1.
MORAES, Fabiana. É tu nada, estrela: revista Caras e o consumo da felicidade nos salóes de beleza de periferia. Tese de Doutorado em Sociologia (mimeo). Recife: Universidade Federal de Pernambuco, 2011.

O OBSERVADOR Brasil 2012. Barueri: Cetelem BGN/ IPSOS, 2012. Disponível em: < http://www.cetelem.com. br/portal/Sobre_Cetelem/Observador.shtml $>$. Acesso em 13 jan. 2013.

ROCHA, Maria Eduarda da Mota. 0 consumo precário: pobreza e cultura de consumo em São Miguel dos Milagres. Maceió: Edufal, 2002.

SLATER, Don. Cultura de consumo e modernidade. São Paulo: Nobel, 2002. 
What are you hungry for?: Gastronomic journalism in Brazilian contemporary consumer culture

\section{De qué tienes hambre?: el periodismo gastronómico en la cultura de consumo brasileña contemporánea}

\section{Resumen}

Abstract

This paper examines how gastronomic journalism is related to Brazilian contemporary consumer culture. Therefore, we resort to concepts such as imaginative hedonism (Campbell); taste, distinction and lifestyle (Bourdieu); and renovation of desire by fashion (Lipovetsky). The corpus includes the section Food of Folha de S. Paulo newspaper, a pioneer as an independent section about this subject published between 1988 and 1992 and reissued in 2011. The cultural phenomenon of gastronomy is observed in the context of the growing of the middle class in the country, when more people start eating out and thinking more about what they eat, looking for information on the subject to guide their choices.

\section{Keywords}

Gastronomic journalism. Consumer culture. Taste.
Este artículo examina cómo el periodismo gastronómico se relaciona con la cultura de consumo contemporánea brasileña. Para ello, se recurre a conceptos como el hedonismo imaginativo, de Campbell; el gusto, la distinción y el estilo de vida, de Bourdieu; y la renovación del deseo pela moda, de Lipovetsky. El corpus está compuesto del caderno Comida, del periódico Folha de S. Paulo, uno de los pioneros como caderno independiente sobre el tema entre 1988 y 1992 y reeditado en 2011. El fenómeno cultural de la gastronomía se observa en el contexto de la creciente clase media en Brasil, cuando más personas empezaron a comer fuera de casa y pensar más en lo que comen, en busca de información sobre el tema para orientar sus decisiones.

\section{Palabras-Clave}

Periodismo gastronômico. Cultura de consumo. Gusto. 


\section{Expediente}

A revista E-Compós é a publicação científica em formato eletrônico da Associação Nacional dos Programas de Pós-Graduação em Comunicação (Compós). Lançada em 2004, tem como principal finalidade difundir a produção acadêmica de pesquisadores da área de Comunicação, inseridos em instituições do Brasil e do exterior.

\section{E-COMPÓS I www.e-compos.org.br I E-ISSN 1808-2599}

Revista da Associação Nacional dos Programas

de Pós-Graduação em Comunicacão.

Brasília, v.17, n.3, set./dez. 2014

A identificação das edições, a partir de 2008

passa a ser volume anual com três números.

\section{CONSELHO EDITORIAL}

Afonso Albuquerque, Universidade Federal Fluminense, Brasil Alberto Carlos Augusto Klein, Universidade Estadual de Londrina, Brasil Alex Fernando Teixeira Primo, Universidade Federal do Rio Grande do Sul, Brasil Rio Grande do Sul, Brasi

Ana Gruszynski, Universidade Federal do Rio Grande do Sul, Brasil Ana Silvia Lopes Davi Médola, Universidade Estadual Paulista, Brasil André Luiz Martins Lemos, Universidade Federal da Bahia, Brasi Ângela Freire Prysthon, Universidade Federal de Pernambuco, Brasil Antônio Fausto Neto, Universidade do Vale do Rio dos Sinos, Brasil Antonio Carlos Hohlfeldt, Pontifícia Universidade Católica do Rio Grande do Sul, Brasil Antonio Roberto Chiachiri Filho, Faculdade Cásper Líbero, Brasi Arlindo Ribeiro Machado, Universidade de São Paulo, Brasil Arthur Autran Franco de Sá Neto, Universidade Federal de São Carlos, Brasil Benjamim Picado, Universidade Federal Fluminense, Brasil César Geraldo Guimarães, Universidade Federal de Minas Gerais, Brasil Cristiane Freitas Gutfreind, Pontifícia Universidade Católica do Rio Grande do Sul, Brasil Denilson Lopes, Universidade Federal do Rio de Janeiro, Brasil Denize Correa Araujo, Universidade Tuiuti do Paraná, Brasil Edilson Cazeloto, Universidade Paulista, Brasil

Eduardo Vicente, Universidade de São Paulo, Brasil

Eneus Trindade, Universidade de São Paulo, Brasil

Erick Felinto de Oliveira, Universidade do Estado do Rio de Janeiro, Brasil Florence Dravet, Universidade Católica de Brasilia, Brasil

Gelson Santana, Universidade Anhembi/Morumbi, Brasi Gilson Vieira Monteiro, Universidade Federal do Amazonas, Brasil Gislene da Silva, Universidade Federal de Santa Catarina, Brasil Guillermo Orozco Gómez, Universidad de Guadalajara, México Gustavo Daudt Fischer, Universidade do Vale do Rio dos Sinos, Brasil Hector Ospina, Universidad de Manizales, Colômbia Herom Vargas, Universidade Municipal de São Caetano do Sul, Brasil leda Tucherman, Universidade Federal do Rio de Janeiro, Brasil Inês Vitorino, Universidade Federal do Ceará, Brasil Janice Caiafa, Universidade Federal do Rio de Janeiro, Brasil Jay David Bolter, Georgia Institute of Technology, Estados Unidos Jeder Silveira Janotti Junior, Universidade Federal de Pernambuco, Brasi João Freire Filho, Universidade Federal do Rio de Janeiro, Brasil John DH Downing, University of Texas at Austin, Estados Unidos Ana Carolina Damboriarena Escosteguy, Pontifícia Universidade Católica do

José Afonso da Silva Junior, Universidade Federal de Pernambuco, Brasil José Carlos Rodrigues, Pontifícia Universidade Católica do Rio de Janeiro, Brasil José Luiz Aidar Prado, Pontifícia Universidade Católica de São Paulo, Brasil José Luiz Warren Jardim Gomes Braga, Universidade do Vale do Rio dos Sinos, Brasil Juremir Machado da Silva, Pontifícia Universidade Católica do Rio Grande do Sul, Brasil Laan Mendes Barros, Universidade Metodista de São Paulo, Brasi Lance Strate, Fordham University, USA, Estados Unidos Lorraine Leu, University of Bristol, Grã-Bretanha Lucia Leão, Pontifícia Universidade Católica de São Paulo, Brasil Luciana Panke, Universidade Federal do Paraná, Brasil Luiz Claudio Martino, Universidade de Brasília, Brasil Malena Segura Contrera, Universidade Paulista, Brasil Márcio de Vasconcellos Serelle, Pontifícia Universidade Católica de Minas Gerais, Brasil Maria Aparecida Baccega, Universidade de São Paulo e Escola Superior de Propaganda e Marketing, Brasi Maria das Graças Pinto Coelho, Universidade Federal do Rio Grande do Norte, Brasil Maria Immacolata Vassallo de Lopes, Universidade de São Paulo, Brasil Maria Luiza Martins de Mendonça, Universidade Federal de Goiás, Brasil Mauro de Souza Ventura, Universidade Estadual Paulista, Brasil Mauro Pereira Porto, Tulane University, Estados Unidos Nilda Aparecida Jacks, Universidade Federal do Rio Grande do Sul, Brasil Paulo Roberto Gibaldi Vaz, Universidade Federal do Rio de Janeiro, Brasil Potiguara Mendes Silveira Jr, Universidade Federal de Juiz de Fora, Brasil Renato Cordeiro Gomes, Pontifícia Universidade Católica do Rio de Janeiro, Brasil Robert K Logan, University of Toronto, Canadá

Ronaldo George Helal, Universidade do Estado do Rio de Janeiro, Brasil Rosana de Lima Soares, Universidade de São Paulo, Brasi Rose Melo Rocha, Escola Superior de Propaganda e Marketing, Brasil Rossana Reguillo, Instituto de Estudos Superiores do Ocidente, México Rousiley Celi Moreira Maia, Universidade Federal de Minas Gerais, Brasi Sebastião Carlos de Morais Squirra, Universidade Metodista de São Paulo, Brasil Sebastião Guilherme Albano da Costa, Universidade Federal do Rio Grande do Norte, Brasil

Simone Maria Andrade Pereira de Sá, Universidade Federal Fluminense, Brasi Suzete Venturelli, Universidade de Brasília, Brasil

Tiago Quiroga Fausto Neto, Universidade de Brasília, Brasil

Valerio Fuenzalida Fernández, Puc-Chile, Chile

Veneza Mayora Ronsini, Universidade Federal de Santa Maria, Brasi Vera Regina Veiga França, Universidade Federal de Minas Gerais, Brasil

\section{COMISSÃO EDITORIAL}

Cristiane Freitas Gutfreind I Pontifícia Universidade Católica do Rio Grande do Sul, Brasil Irene Machado I Universidade de São Paulo, Brasil

Jorge Cardoso Filho I Universidade Federal do Recôncavo da Bahia, Brasil Universidade Federal da Bahia, Brasil

CONSULTORES AD HOC

Adriana Amaral, Universidade do Vale do Rio dos Sinos, Brasil

Alexandre Rocha da Silva, Universidade Federal do Rio Grande do Sul, Brasi

Arthur Ituassu, Pontifícia Universidade Católica do Rio de Janeiro, Brasil

Bruno Souza Leal, Universidade Federal de Minas Gerais, Brasil

Elizabeth Bastos Duarte, Universidade Federal de Santa Maria, Brasil

Francisco Paulo Jamil Marques, Universidade Federal do Ceará, Brasi

Maurício Lissovsky, Universidade Federal do Rio de Janeiro, Brasil

Suzana Kilpp, Universidade do Vale do Rio dos Sinos, Brasil

Vander Casaqui, Escola Superior de Propaganda e Marketing, Brasi

EDIÇ̃̃O DE TEXTO E RESUMOS I Press Revisão

SECRETÁRIA EXECUTIVA I Helena Stigger

EDITORAÇÃo ELETRÔNICA I Roka Estúdio
COMPÓS I www.compos.org.br

Associação Nacional dos Programas de Pós-Graduação em Comunicação

Presidente

Eduardo Morettin

Universidade de São Paulo, Brasil

eduardomorettin@usp.br

Vice-presidente

Inês Vitorino

Universidade Federal do Ceará, Brasil

ines@ufc.br

Secretária-Geral

Gislene da Silva

Universidade Federal de Santa Catarina, Brasil

gislenedasilva@gmail.com 